\title{
12. STUDY OF TECTONIC DEFORMATION IN SEDIMENTS INTERLAYERED WITH THE BASALTS FROM HOLE 412A, IPOD LEG 49
}

\author{
J. Varet, BRGM - at Geothermie SGN., Orleans, France \\ and \\ P. Choukroune, Dt Sciences de la Terre, Université de Rennes, Rennes, France
}

\section{INTRODUCTION}

Site 412A (Figure 1) is on the north side of a fracture zone valley. One hundred thirty-one meters of basaltic flows were recovered at a 2763 -meter depth below sea level $(163 \mathrm{~m}$ sub-bottom depth). On simple transform fault theory, the crust at this site $-1.6 \mathrm{~m}$.y. old, according to magnetic interpretations - having accreted on the moving part of the African plate, would never have been deformed by transform fault activity.

Relatively good recovery of lower Pleistocene sediments intercalated in the basalts of Core $14(50 \mathrm{~cm}$ recovered, Figure 2) allowed us to observe deformations consisting mainly of striated fault planes (slickensides). Samples were studied on board by Varet, and in laboratory by Choukroune. Detailed laboratory study of the samples was limited for technical reasons.

Observations of tectonized sediments, either recovered by drilling or observed in situ, allow us to define the character and origin of deformations occurring on the sea floor (Choukroune et al., in press).

\section{GENERAL CHARACTERISTICS OF THE SAMPLES (412A-14, 10 to $412 \mathrm{~A}-14,14)$}

Samples are composed exclusively of indurated nannofossil chalk ( $95 \%$ nannofossils) with traces of volcanogenic silt and clay and well-developed stratification. Bedding is tilted 10 to 30 per cent; all samples show deformation with fracturing (small-scale faulting with slickensides on fault planes). Only Sample 4 shows horizontal striations (with the core place vertical). Samples 5 to 10 show striations with significant pitch on the planes of normal microfaults. Fault planes are generally underlined by striated black to light brown limonite or manganese oxide coating.

\section{SAMPLE DESCRIPTION}

\section{Sample 4}

The core sample is $10 \mathrm{~cm}$ long and two tectonized zones are visible. The first, at the base of the sample, shows two parallel fault planes inclined at $60^{\circ}$ when the core is vertical. The pitch of the striations, always weak, varies from $10^{\circ}$ to $25^{\circ}$. Such striations indicate strike-slip motion along these microfaults (see Plate 1). The second occurs toward the top of the sample. Here, the core is broken along an irregular surface showing undulations with an amplitude measured in centimeters. The surface envelope of these undulations has a dip of $30^{\circ}$ when the core is vertical. Visible striations have a very weak pitch with respect to the horizontal of this surface envelope, which describes a very small angle with the $S_{0}$ stratification. In this case also, we assume the presence of strike-slip microfaults (see Plate 2).

The sense of motion along this surface envelope could have been confirmed by a laboratory examination of the detailed morphology of the microfractured area:

1) relativedisposition of striated microplanes with respect to one another;

2) relative disposition of striated microplanes with respect to surfaces;

3) relative disposition of striated microplanes with respect to dissolution surfaces;

4) relative position of eventual Riedel planes with respect to the envelope surface considered.

This examination could not be done in the laboratory, but on-board observations and, in particular the observation of Riedel planes, as well as repartition of striation on the irregular surface of fault, allowed us to define a right-lateral sense of motion along this fault plane.

\section{Sample 5}

This sample (Plate 3) shows a series of microcracks with an important dip $\left(75^{\circ}\right)$ when the core is placed vertically. These microcracks are parallel to each other. The surface of these microfaults is not coated with manganese. The horizontal direction in fault planes makes a very small angle with the horizontal of $\mathrm{S}_{0}$.

It is possible to use the relative disposition of $\mathrm{S}_{0}$ planes to define the sense of relative displacement: the display of the $S_{0}$ planes as well as striations with a significant pitch on the planes of the microfaults indicate that we have microfracturation in tension (normal faults) (Plate 4).

\section{Sample 8}

This sample shows a striated fault plane, coated with oxides. The fault plane is nearly vertical when the core is vertical. Dip of $S_{0}$ is nearly $30^{\circ}$. Striations have a pitch of nearly $90^{\circ}$. Stratification locally shows "boundinage" phenomena (lengthening), probably contemporaneous with compaction of the sediments, and compatible with the movement observed along the normal fault.

\section{Samples 9 and 10}

The samples display a microfault surface (Plate 6). The surface of the striated microfaults is nearly vertical, with pitch of $90^{\circ}$. The movement is vertical and probably in tension.

\section{CONCLUSION}

Two types of fault planes occur in the deformed sediments of Hole 410A. 


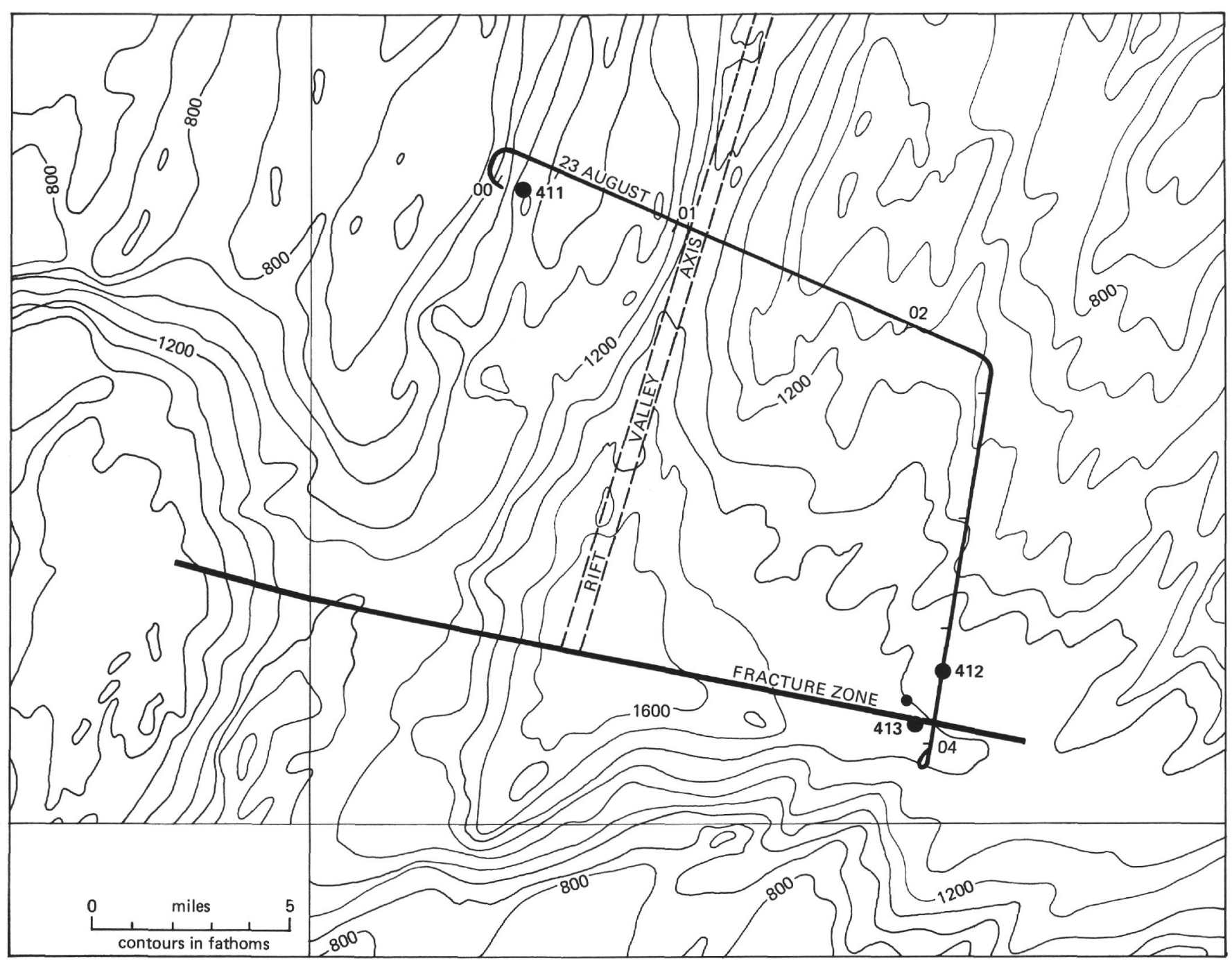

Figure 1. Bathymetric map of FAMOUS area showing the location of Sites 411, 412, and 413 and Glomar Challenger track during Leg 49. Rift valley axis, as well as fracture zone, is indicated schematically. Bathymetry from Phillips et al., in preparation.

1) Normal faults, with a vertical or nearly vertical displacement movement (tension).

2) Strike-slip faults, with horizontal or nearly horizontal displacement. Fault planes with small step-like parting surfaces oriented at nearly right angles to the plane of movement and the slickenside lineation indicate right-lateral motion.

The relative disposition of these two types of deformations could not be observed directly. However, both fault plane types are roughly parallel to the bedding. Assuming that slickensided fault strikes are oriented east-west, these observations suggest that normal faulting, block tilting, and rightlateral strike-slip motion occurred along the eastern part of Fracture Zone B, away from the transform fault. Strike-slip faulting, as well as normal faulting, both parallel to block tilting, occurred in a fracture zone: this agrees perfectly with fracture zone morphology. The sense of motion is, however, opposite to what should be expected if this resulted from ancient transform activity of Transform Fault B (Whitmarsh and Laughton, 1975). Slight right-lateral readjustments may, however, be occurring along Atlantic fracture zones away from transform faults (Ball and Harrison, 1970).

\section{REFERENCES}

Ball, M.N. and Harrison, C.G.A., 1970. Crustal plates in the central Atlantic, Science, v. 167, p. 1128-1129.

Choukroune, P., Francheteau, J., and Le Pichon, X., in press. In-situ structural observations along transform fault $A$ in the FAMOUS area, Mid-Atlantic Ridge, Geol. Soc. Am. Bull.

Phillips, J.D., Fleming H., and Brundage, W., in preparation. Geol. Soc. Am. Bull.

Whitmarsh, R.B. and Laughton, A.S., 1975. The fault pattern of a slow-spreading ridge near a fracture zone, Nature, v. 258, p. 509-510. 


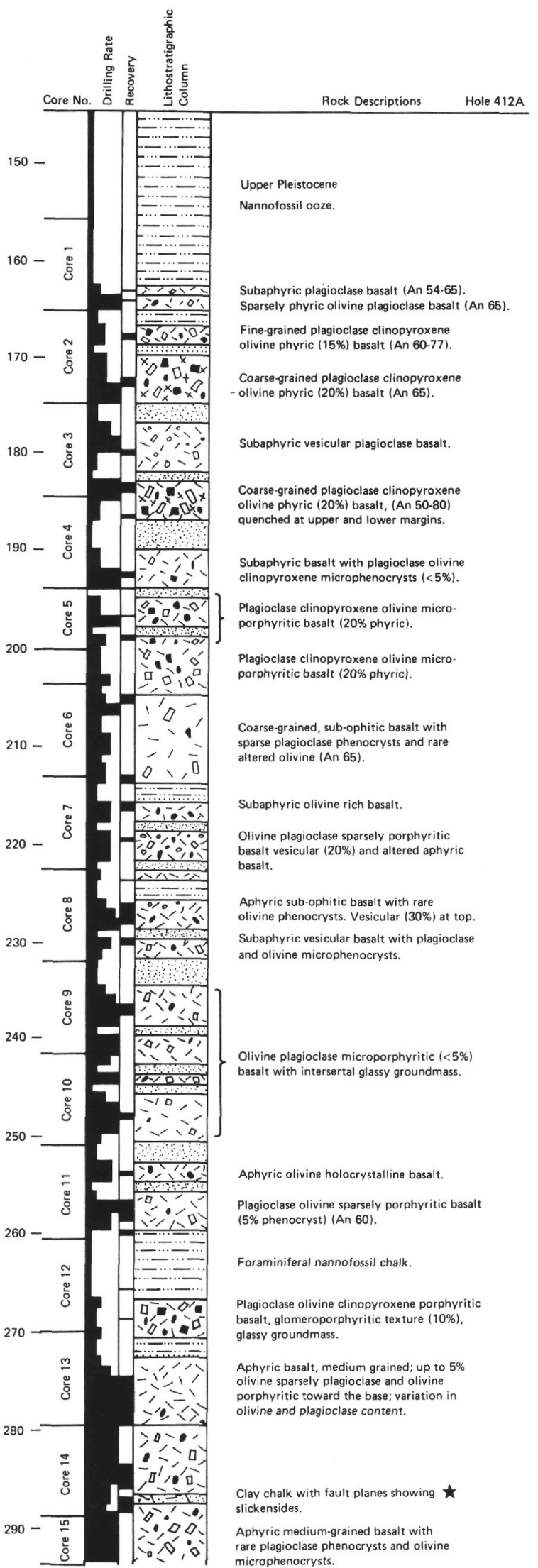

Figure 2. Simplified stratigraphic section of Hole $412 \mathrm{~A}$ showing the location of the sediments affected by slicken-sides. 


\section{PLATE 1}

Horizontal slickensides on a fault plane inclined at $30^{\circ}$ in the upper part of Piece 4. Scale in $\mathrm{mm}$.

\section{PLATE 2}

Detailed photograph of slickensides on the upper part of Piece 4B. A right lateral motion is deduced from the repetition of striated planes.

Scale in $\mathrm{mm}$.

(see p. 432)

\section{PLATE 3}

Detailed photograph of a section through Piece 5, indicating that normal faults are parallel to bedding.

(see p. 433)

\section{PLATE 4}

Detailed photograph showing vertical striations on a vertical fault plane all along Piece 8.

(see p. 434)

\section{PLATE 5}

Vertical striation along vertical fault plane in Piece 9.

(see p. 434)

\section{PLATE 6}

Normal vertical fault plane parallel to bedding in Piece 10 .

(see p. 435) 
TECTONIC DEFORMATION IN BASALTS

PLATE 1
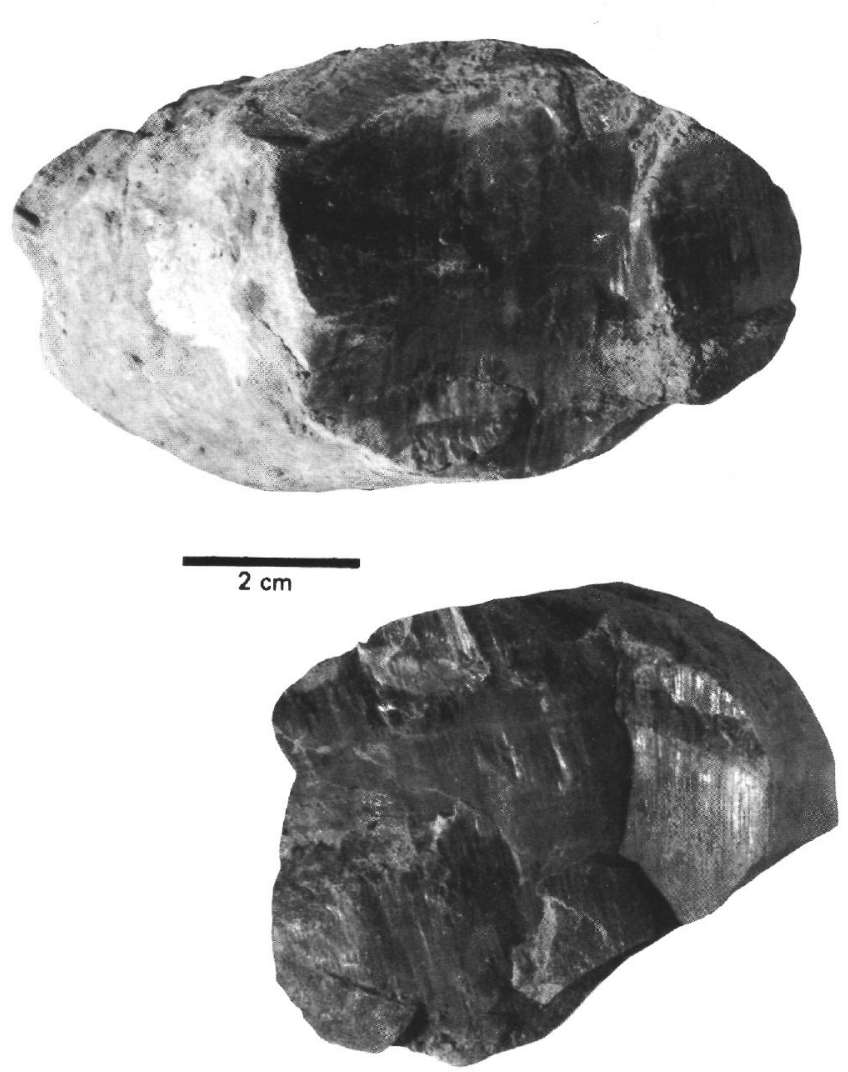


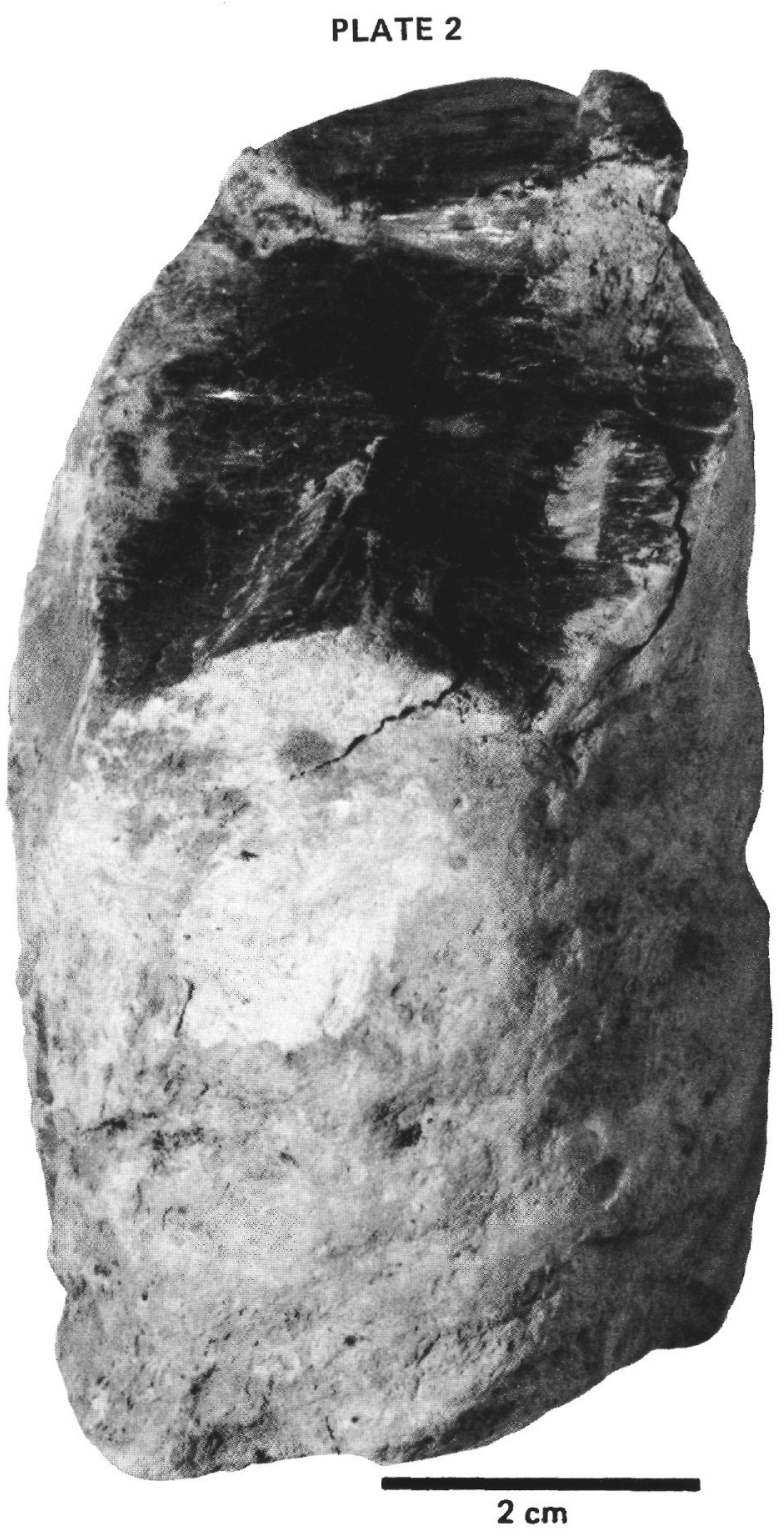




\section{PLATE 3}

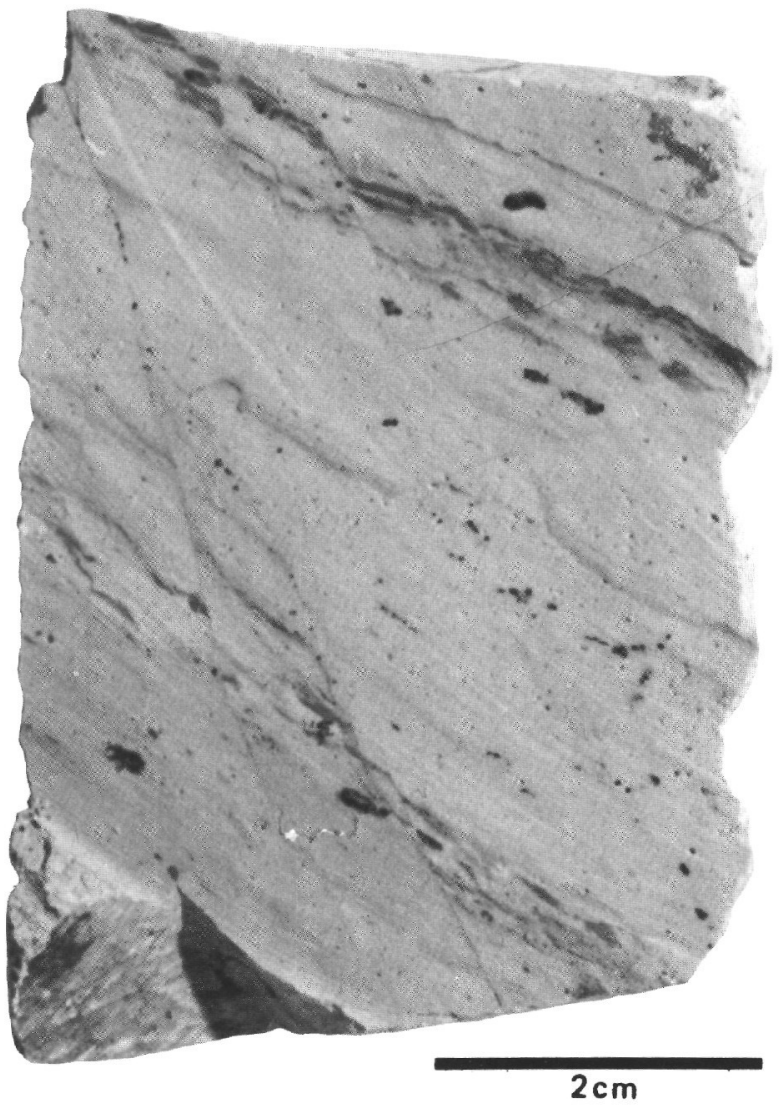


J. VARET, P. CHOUKROUNE

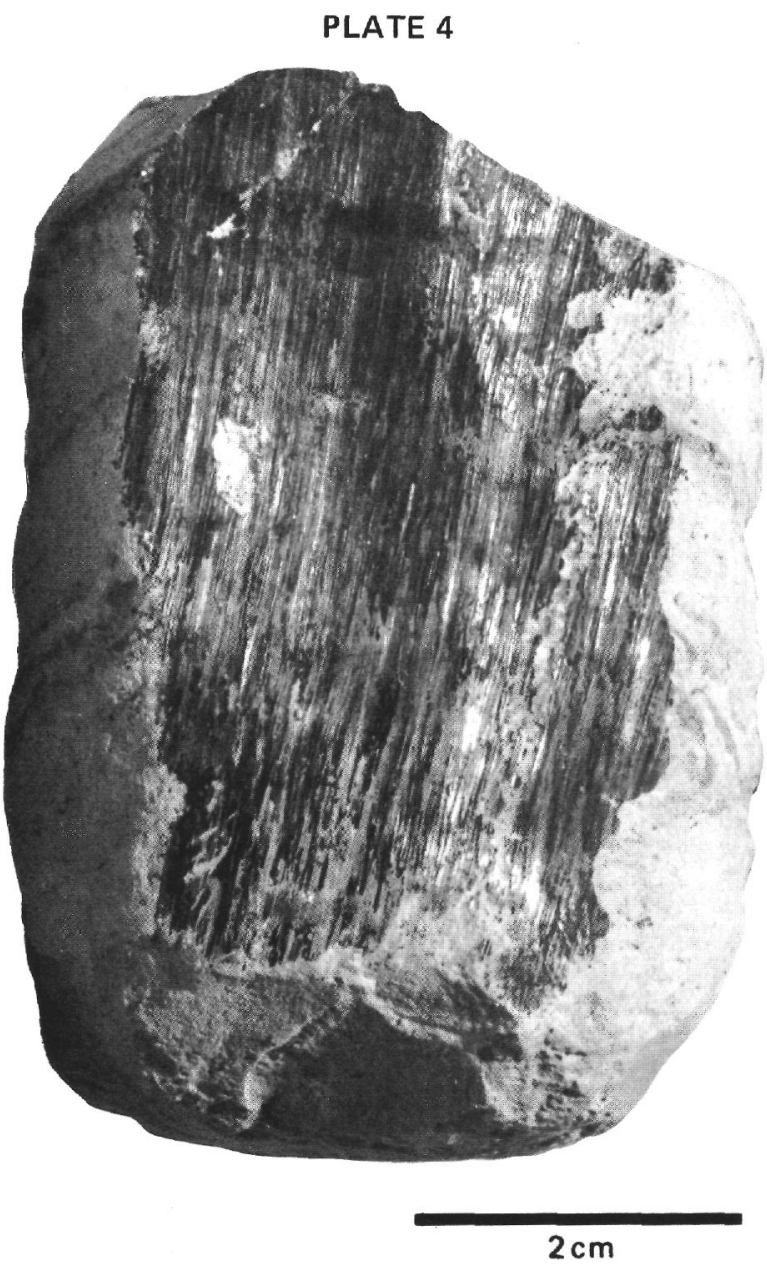

PLATE 5

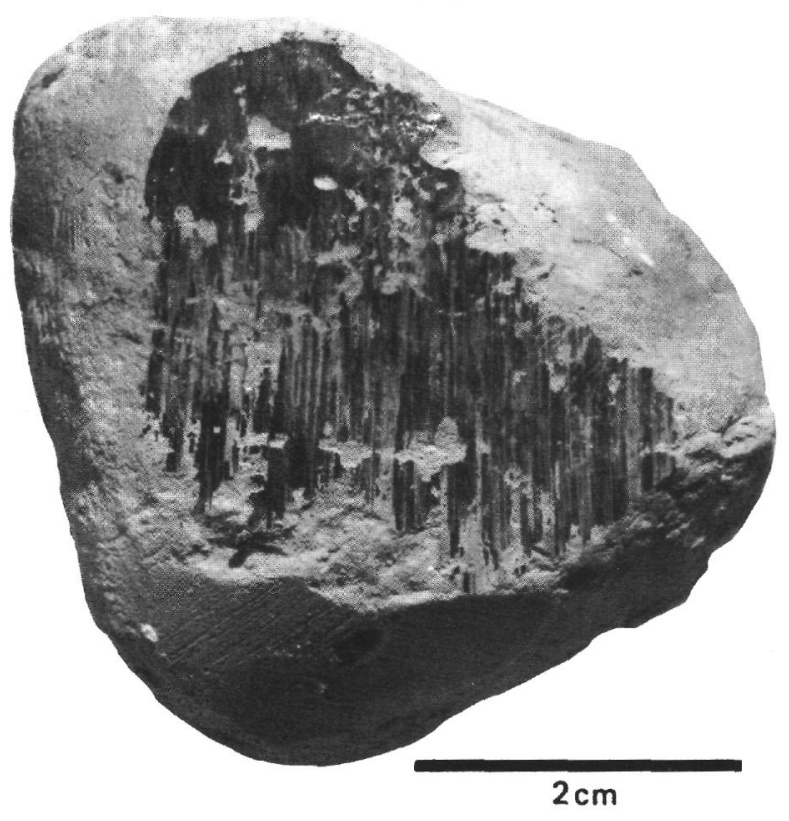


PLATE 6

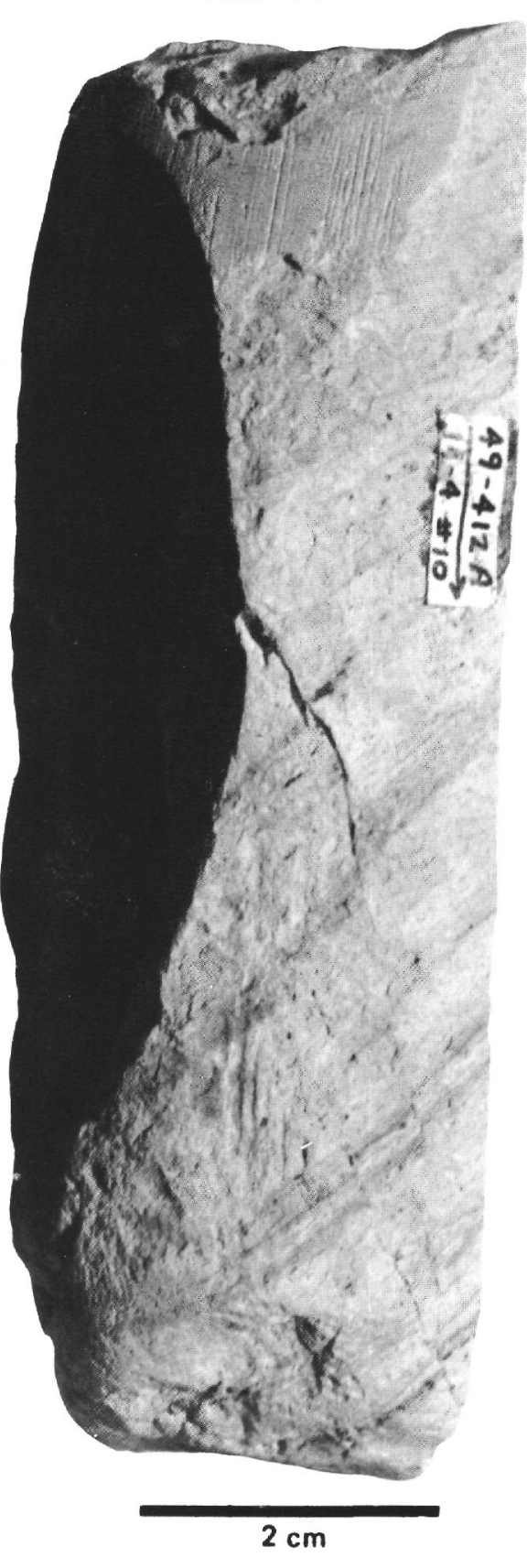

